\title{
Association of dietary habits with restorative dental treatment need and BMI among Finnish conscripts: a cross-sectional epidemiological study
}

\author{
Tarja Tanner ${ }^{1, *}$, Pernelle Moilanen ${ }^{1}$, Jari Päkkilä2 ${ }^{2}$ Pertti Patinen ${ }^{3}$, Leo Tjäderhane ${ }^{1,4,5}$ \\ and Vuokko Anttonen ${ }^{1,4}$ \\ 'Department of Cariology, Endodontology and Pediatric Dentistry, Research Unit of Oral Health Sciences, University of \\ Oulu, PO Box 5281, Fl-90014 Oulu, Finland: '2Department of Mathematical Sciences, University of Oulu, Oulu, \\ Finland: ${ }^{3}$ Centre for Military Medicine, Finnish Defence Forces, Riihimäki, Finland: ${ }^{4}$ Medical Research Unit, Oulu \\ University Hospital and University of Oulu, Oulu, Finland: ${ }^{5}$ Department of Oral and Maxillofacial Diseases, University \\ of Helsinki MRC, Helsinki, Finland
}

Submitted 19 June 2018: Final revision received 7 April 2019: Accepted 23 April 2019; First published online 7 August 2019

\begin{abstract}
Objective: Processed foods and fatty, sugary snacking products, such as fizzy drinks and desserts, have become more popular, causing a desire to replace meals with snacks worldwide. High-sugar and fat-rich food components have been reported to be associated with increased level of dental caries as well as underweight and overweight. The aim of the present cross-sectional population-based study was to analyse the eating behaviours of young, healthy Finnish males in association with oral health and BMI, considering self-reported and residential background factors.

Design: Cross-sectional study.

Setting: Finnish Defence Forces, Finland.

Participants: The used clinical data were gathered from 13564 Finnish conscripts born in the beginning of the 1990s through clinical check-ups. In addition, about 8700 of the conscripts answered a computer-assisted questionnaire ('Oral Health of the Conscripts 2011' data) about their background information and health habits. Results: There was distinct variation in dietary patterns. Eating breakfast, regular physical exercise and daily tooth brushing all decreased the odds for restorative dental treatment need (decayed teeth), whereas smoking and drinking fizzy drinks for quenching thirst increased it. Eating breakfast and dinner were each associated with lower BMI, but smoking increased the odds for higher BMI $\left(\geq 25 \mathrm{~kg} / \mathrm{m}^{2}\right)$. Conclusions: Regular, proper meals and especially eating breakfast decreased the odds for both dental caries and high BMI $\left(\geq 25 \mathrm{~kg} / \mathrm{m}^{2}\right)$.
\end{abstract}

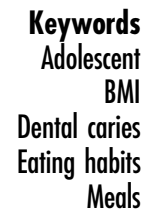

The decrease in dental caries prevalence observed in the Western world in the last decades is believed to be due to regular use of fluoride products ${ }^{(1)}$. Healthy eating habits also play an important role in maintaining oral health ${ }^{(2,3)}$. Yet the eating habits of young people are going through significant changes worldwide, with processed and fast foods and fizzy drinks being consumed more frequently than ever before ${ }^{(4)}$. This kind of a diet includes plenty of processed sugars, added sugars and fats ${ }^{(4)}$; and sugars consumed by children are associated with future dental caries prevalence ${ }^{(5)}$.

The free school lunch has been available for all Finnish schoolchildren since the 1950s. However, recently there has been discussion about Finnish adolescents not eating their school lunch in its entirety as intended. According to a Finnish survey, the warm course of the school lunch is the main component, yet only half reported eating the salad or grated vegetables daily ${ }^{(6)}$. Finnish nutrition guidelines recommend a regular eating rhythm with six meals daily, including healthy snacks recommended once or twice per day. Snacks are sometimes necessary due to individual differences in energy consumption, but effort is put into preventing constant snacking ${ }^{(7)}$.

Skipping meals like school lunch may lead to a desire to replace it with snacking products like soft drinks. In 
addition, use of water as a thirst quencher is often replaced with fizzy drinks and juices ${ }^{(8)}$, which contain an extensive amount of unnecessary sugars and thus energy ${ }^{(9)}$. In an Australian follow-up study, children's overweight was associated with sweet drink consumption and dental problems additionally with consumption of fatty foods. Both under- and overweight were associated with future dental caries incidence ${ }^{(10)}$.

The prevalence of overweight and obese children in their early teens has increased in Finland in recent decades, specifically among boys ${ }^{(11)}$. In a Swedish study, oral health per se but also oral health behaviours of obese adolescents were poorer compared with those of normal-weight teenagers $^{(12)}$.

The aim of the present cross-sectional population-based study was to analyse the dietary behaviours of healthy Finns in their early twenties. Another aim was to evaluate the association of their BMI and eating behaviours with indicators of dental caries and periodontal disease. We hypothesized that poor oral health associates with irregular eating behaviours and with high BMI values.

\section{Methods}

The study material was based on the 'Oral Health of the Conscripts 2011' project data ${ }^{(13)}$. The survey group comprised conscripts born in early 1990 s entering their military service in 2011 ( $n 13$ 819; males 98.2\%) ${ }^{(14)}$. The data were collected during the first two weeks of the military service. Due to the small proportion of female conscripts in the study population ( $n$ 255), their data were not analysed separately or compared with the male study population. The protocol, criterions and calibration, and internal and external validity of clinical examinations have been described in detail in previously published articles ${ }^{(13,15,16)}$.

\section{Questionnaire}

About 8700 conscripts answered a computer-based questionnaire. The number of responses varied slightly for different questions (Table 1). The following questions on eating habits were selected for the present study: 'How often do you eat the following meals by sitting at the table? (breakfast, lunch, dinner, supper)' and 'How often do you eat the following components of a meal? (warm meal, salad or grated vegetables, bread or crispbread)'. For all of these questions, the answering options were 'never or hardly ever', 'every day or almost every day' or 'occasionally during the week'.

For the questions 'What do you usually drink with your meals?' and 'What do you usually drink for your thirst?', the following options were provided: milk, juice, concentrated juice, tap water, general fizzy drink, light fizzy drink, light concentrated juice, bottled water and something else (one choice). Juice and concentrated juice were analysed as the category 'juice', bottled water and tap water as 'water', and light fizzy drink and light concentrated juice as 'light drinks'; leaving general fizzy drink in the category 'fizzy drink'.

Education level (comprehensive school, vocational school, university of applied sciences, dual qualification, high school, university, other) was exploited in the study. Education level was divided into three categories: 'comprehensive or vocational school', 'high school or dual qualification' and 'university or university of applied sciences'. Those reporting their education to be other $(n$ 4) were excluded from the analyses related to education.

For the question 'How often do you participate in sports or physical exercise?', options were 'not at all', '1-2 times a month', '1-2 times a week', '3-4 times a week' and 'more frequently than 5 times a week'. For the question 'How often do you brush your teeth?', options were 'never or hardly ever', 'every day or almost every day' or 'occasionally during the week'. Those who brushed their teeth daily were also asked to answer the subsequent question 'How many times a day do you brush your teeth?' (response options of 'once a day', 'twice a day', 'more frequently than twice a day'). For the question 'Do you smoke?', the options were 'no', '1-5 cigarettes a day', '10-20 cigarettes a day' and 'over 20 cigarettes a day'. In the present study, the status of

Table 1 Distribution of eating different meals and meal components and health-related habits in the study population of $\sim 8700$ Finnish conscripts born in the beginning of the 1990s (data from the 'Oral Health of the Conscripts 2011' project)

\begin{tabular}{|c|c|c|c|c|c|}
\hline & $\begin{array}{l}\text { Never or hardly } \\
\text { ever }(\%)\end{array}$ & Occasionally (\%) & Regularly (\%) & Total (\%) & $N$ \\
\hline \multicolumn{6}{|l|}{ Meal } \\
\hline Breakfast & $19 \cdot 8$ & $20 \cdot 9$ & $59 \cdot 3$ & $100 \cdot 0$ & 8699 \\
\hline Lunch & $9 \cdot 8$ & 22.9 & $67 \cdot 3$ & $100 \cdot 0$ & 8699 \\
\hline Dinner & $3 \cdot 8$ & $16 \cdot 8$ & 79.5 & $100 \cdot 0$ & 8699 \\
\hline Supper & $9 \cdot 1$ & $26 \cdot 8$ & $64 \cdot 2$ & $100 \cdot 0$ & 8691 \\
\hline \multicolumn{6}{|l|}{ Meal component } \\
\hline Warm course & 0.3 & 3.9 & $95 \cdot 8$ & $100 \cdot 0$ & 8693 \\
\hline Salad or grated vegetables & $12 \cdot 1$ & 40.5 & 47.4 & $100 \cdot 0$ & 8693 \\
\hline Bread or crispbread & $6 \cdot 0$ & $27 \cdot 3$ & $66 \cdot 7$ & $100 \cdot 0$ & 8693 \\
\hline Physical exercise & $5 \cdot 2$ & $16 \cdot 3$ & $78 \cdot 6$ & $100 \cdot 0$ & 8700 \\
\hline Tooth brushing & 1.0 & 9.5 & 89.5 & $100 \cdot 0$ & 8685 \\
\hline Smoking & $60 \cdot 9$ & - & $39 \cdot 1$ & $100 \cdot 0$ & 8687 \\
\hline
\end{tabular}


smoking was dichotomized into those who did not smoke at all and the rest.

Urban-rural division as well as division according to the language mainly spoken in the home municipality were done as described earlier by Kämppi et al. ${ }^{(14)}$. Places of residence were dichotomized into those where only or mainly Finnish was spoken and those where only or mainly Swedish was spoken.

The term 'regularly' was used for tasks performed every day or almost every day for the questions related to meals and tooth brushing and weekly for the question concerning the regularity of exercising. The term 'occasionally' referred to the options 'occasionally during the week' for the questions concerning meals and tooth brushing and ' $1-2$ times a month' for the question covering physical exercise.

\section{Clinical parameters}

BMI values of the conscripts were calculated according to the height and weight data measured in the obligatory medical examination during the first two weeks of military service. As commonly accepted, persons with BMI $\geq$ $25 \mathrm{~kg} / \mathrm{m}^{2}$ were considered overweight/obese and those with BMI $<25 \mathrm{~kg} / \mathrm{m}^{2}$ as normal weight.

Decayed teeth (DT) and decayed, missing and filled teeth due to dental caries (DMFT) were determined as described in a previous study ${ }^{(13)}$. As for periodontal status, mean Community Periodontal Index (CPI) per sextant was used. The mean of the six CPI scores was calculated for each person once all six values were available. Bleeding on probing (BOP) was also reported by sextant (bleeding/no bleeding), reaching the values $0-6^{(16)}$.

\section{Statistics}

Distributions of the eating behaviours in the study population were described as frequencies and proportions, also categorizing the participants according to their place of residence, education level, BMI and health behaviours. Mean values and SD were calculated for different oral health measures. Variables were created to investigate the association of the number of consumed daily meals and meal components with oral health measures. To investigate the association between BMI and dental caries, dichotomized DT values $(0-2, \geq 3)$ were investigated with categorized BMI values $\left(<17,17 \cdot 01-25,25 \cdot 01-30,>30 \mathrm{~kg} / \mathrm{m}^{2}\right)$. Cross-tabulation and $\chi^{2}$ tests were used to analyse the significance of the differences between the variables. Binary logistic regression analysis was used to study the association of the need for restorative dental treatment (DT $>0$ ) or BMI $\geq 25 \mathrm{~kg} / \mathrm{m}^{2}$ with explanatory variables. $P$ values $<0.05$ were considered statistically significant. Drink consumption was illustrated graphically as a bar plot.

The analyses were performed using the statistical software package IBM SPSS Statistics for Windows version 22.0 (2013) and R software version 3 (2014).

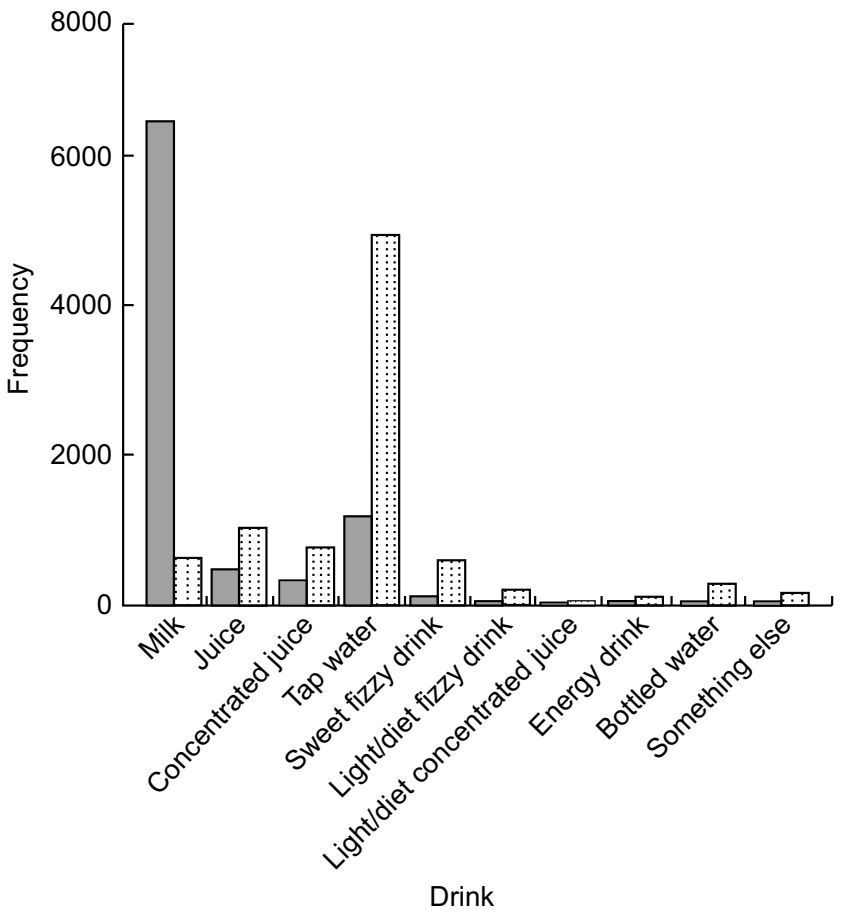

Fig. 1 Drink consumption at meals $(\square)$ and for quenching thirst (ت) in the study population of $\sim 8700$ Finnish conscripts born in the beginning of the 1990s (data from the 'Oral Health of the Conscripts 2011' project)

\section{Results}

The number of daily meals varied from no regular meals (6.5\%) to one (9.4\%), two or three $(52.6 \%)$, or even four meals $(31.6 \%)$ per day. Dinner was the most frequently eaten meal followed by lunch. Yet almost four in ten conscripts skipped lunch at least occasionally during the week; $20 \%$ ate it hardly ever or never (Table 1). Milk was by far the most common drink at meals, followed by water and juice; whereas the drinks most frequently used for quenching thirst were water, juice, fizzy drinks and milk (Fig. 1). A similar trend was seen with the components of meals: $2 \cdot 4 \%$ recorded no meal components, $61.9 \%$ had one or two, and about a third (35.8\%) had all three meal components. The mean frequency of consumed daily meals was 2.7 and meal components $2 \cdot 1$. The most frequently eaten meal component was the warm course alongside bread, whereas the most frequently skipped meal component was salad or grated vegetables (Table 1). Most conscripts reported regularly doing physical exercise and brushing their teeth daily. Almost $40 \%$ reported smoking daily (Table 1).

The more daily meals and meal components conscripts ate, the less dental treatment they needed (Table 2). Conscripts drinking water for quenching thirst had less need for restorative and periodontal treatment compared with those drinking fizzy drinks (Table 2). Need for restorative dental care $(\mathrm{DT}>0)$ was significantly greater $(P<0.001)$ for those who did not eat regularly: the proportions were $53 v .43 \%$ for breakfast, $50 v$. $46 \%$ for lunch, 
Table 2 Percentages and mean values for different oral health measures according to eating and drinking habits in the study population of 8700 Finnish conscripts born in the beginning of the 1990s (data from the 'Oral Health of the Conscripts 2011' project)

\begin{tabular}{|c|c|c|c|c|c|c|c|c|c|c|}
\hline \multirow{2}{*}{\multicolumn{2}{|c|}{$\begin{array}{l}\text { Meals and meal components (sum) } \\
\text { and drinks for quenching thirst }\end{array}$}} & \multirow{2}{*}{$\begin{array}{l}\text { Need for restorative } \\
\text { dental care }(\%)\end{array}$} & \multicolumn{2}{|c|}{ DMFT } & \multicolumn{2}{|c|}{ CPI } & \multicolumn{2}{|c|}{$\begin{array}{l}\text { Number of } \\
\text { BOP areas }\end{array}$} & \multicolumn{2}{|c|}{ BMI $\left(\mathrm{kg} / \mathrm{m}^{2}\right)$} \\
\hline & & & Mean & SD & Mean & SD & Mean & SD & Mean & SD \\
\hline \multirow{5}{*}{ Number of meals } & 0 & $57 \cdot 1$ & $5 \cdot 0$ & 4.72 & 0.7 & 0.54 & 2.7 & $2 \cdot 12$ & 24.8 & $4 \cdot 32$ \\
\hline & 1 & $51 \cdot 1$ & 4.9 & 4.41 & 0.7 & 0.54 & 2.7 & $2 \cdot 11$ & 24.7 & 4.44 \\
\hline & 2 & $50 \cdot 0$ & $4 \cdot 7$ & 4.46 & 0.7 & 0.53 & 2.8 & $2 \cdot 12$ & 24.6 & 4.37 \\
\hline & 3 & $46 \cdot 9$ & $4 \cdot 1$ & $4 \cdot 27$ & 0.6 & 0.49 & 2.5 & 2.03 & 24.0 & 4.23 \\
\hline & 4 & $42 \cdot 1$ & $3 \cdot 7$ & 3.78 & 0.6 & 0.50 & 2.3 & $2 \cdot 00$ & 23.7 & 3.65 \\
\hline \multirow[t]{4}{*}{ Number of meal components } & 0 & $60 \cdot 6$ & $5 \cdot 4$ & $4 \cdot 74$ & 0.7 & 0.53 & 2.7 & 1.99 & 24.7 & $4 \cdot 31$ \\
\hline & 1 & $49 \cdot 6$ & $4 \cdot 6$ & 4.58 & 0.7 & 0.51 & 2.7 & $2 \cdot 11$ & 24.2 & 4.47 \\
\hline & 2 & $47 \cdot 0$ & $4 \cdot 3$ & $4 \cdot 22$ & 0.7 & 0.52 & 2.5 & 2.05 & 24.0 & 4.09 \\
\hline & 3 & $44 \cdot 8$ & 3.9 & 3.98 & 0.6 & 0.50 & 2.4 & 2.04 & 24.4 & 3.97 \\
\hline \multirow[t]{2}{*}{ Drinks } & Water & $45 \cdot 2$ & $4 \cdot 0$ & 4.03 & 0.6 & 0.50 & 2.4 & $2 \cdot 03$ & 24.3 & $4 \cdot 13$ \\
\hline & Fizzy drink & $58 \cdot 8$ & $5 \cdot 5$ & 4.98 & 0.7 & 0.54 & 3.0 & $2 \cdot 18$ & 23.7 & $4 \cdot 20$ \\
\hline Total & & $45 \cdot 0$ & $4 \cdot 1$ & $4 \cdot 16$ & 0.7 & 0.54 & 2.7 & 2.08 & 24.2 & $4 \cdot 19$ \\
\hline
\end{tabular}

DMFT, decayed, missing and filled teeth due to dental caries; CPI, Community Periodontal Index; BPO, bleeding on probing.

$52 v .46 \%$ dinner and $49 v .46 \%$ for supper $(P=0.010)$, respectively. A similar correlation was found in terms of the need for periodontal treatment (mean CPI). Need for periodontal care was greater for those who did not regularly eat the warm meal (59\%) or salad/grated vegetables (50\%) compared with those who ate them regularly ( 47 and $44 \%$, respectively; $P<0.001$ ).

The mean BMI in the study population was 24.2 (SD $4 \cdot 19) \mathrm{kg} / \mathrm{m}^{2}$ and two-thirds (65.1\%) had BMI $<25 \mathrm{~kg} / \mathrm{m}^{2}$. Those with BMI $<25 \mathrm{~kg} / \mathrm{m}^{2}$ ate all meals and meal components more frequently than those with $\mathrm{BMI} \geq 25 \mathrm{~kg} / \mathrm{m}^{2}$. The more daily meals conscripts ate, the lower was their BMI. The number of meal components did not seem to have a linear association with BMI value (Table 3).

Those of normal weight had least need for restorative dental care. Compared with normal-weight conscripts, overweight conscripts had more need for restorative (DT > 0: $44.8 v .48 .8 \%$ ) and periodontal treatment (mean CPI: 0.7 (SD 0.55) v. 0.8 (SD 0.57)), higher caries experience (mean DMFT: 4.0 (SD 4.08) v. $4.4(\mathrm{SD} 4.21)$ ) and higher mean BOP (2.5 (SD 2.10) v. $2 \cdot 8$ (SD 2.14)). Overweight conscripts brushed their teeth daily slightly less often ( $87.5 \%)$ than those of normal weight $(90.6 \% ; P<0.001)$. Also, a larger proportion of normal-weight conscripts brushed their teeth twice daily or more often (61\%) compared with overweight conscripts ( $55 \% ; P<0.001)$.

Those living in rural communities ate all other meals except dinner slightly more frequently compared with their urban counterparts. Almost all conscripts from the Swedish-speaking communities ate all other meals except supper and the warm course distinctly more frequently than the ones from Finnish-speaking municipalities. Conscripts with higher education more regularly ate meals and all different meal components than conscripts with lower education (Table 3). Furthermore, those who smoked clearly ate fewer meals and meal components, consumed less water and more frequently used fizzy drinks for quenching thirst compared with their non-smoking counterparts. The same was true for those who brushed their teeth daily or did regular physical exercise, compared with those who did not (Table 3).

Binary logistic regression analyses showed that eating breakfast was negatively associated with restorative dental treatment need $(P<0.001)$, as was regular physical exercise $(P<0.01)$ and daily tooth brushing $(P<0.001)$. However, smoking and drinking fizzy drinks for quenching thirst increased the odds for restorative treatment need $(P<0.001)$. According to the binary logistic regression analysis, eating breakfast $(P<0.001)$ and dinner $(P<0.01)$ regularly were each negatively associated with overweight (BMI $\geq 25 \mathrm{~kg} / \mathrm{m}^{2}$ ), whereas smoking increased the odds $(P<0 \cdot 001$; Table 4$)$.

\section{Discussion}

The present cross-sectional population-based study shows that dinner and lunch are the most commonly eaten meals by young healthy Finnish conscripts. A high number of daily meals and meal components as well as eating breakfast were found to be significantly negatively associated with dental caries and overweight. Yet $20 \%$ of conscripts ate breakfast only occasionally and the same proportion ate breakfast never or hardly ever. Finnish men in their early twenties drink milk, water or juice at meals, and water, juice, fizzy drinks or milk for quenching thirst. Smoking increased the odds for both restorative dental treatment need and overweight. Overweight was associated with increased prevalence of restorative and periodontal treatment need in the present study.

Only one-third of Finnish conscripts followed the Finnish meal recommendations (four daily meals and essential meal components) ${ }^{(17)}$. Decreased number of daily meals and meal components seemed to be associated with increased need for dental and periodontal care. Here our findings somewhat support those of Dusseldorp et al. ${ }^{(18)}$. 
Table 3 Association of meals and meal components with behavioural and other variables in the study population of $\sim 8700$ Finnish conscripts born in the beginning of the 1990s (data from the 'Oral Health of the Conscripts 2011' project)

\begin{tabular}{lllllllll}
\hline & & \multicolumn{3}{c}{ Meals and meal components consumed every day or almost every day and drinks } \\
consumed for quenching thirst (\%)
\end{tabular}

Of all the meals, particularly breakfast appeared to play an important role as a protective factor against restorative dental treatment need. This is in line with previous studies ${ }^{(19,20)}$ even if Dusseldorp et al. found that breakfast may be more important among 15-year-olds or younger than young adults $^{(18)}$.

It also appeared that the conscripts with unfavourable health habits (smoking, not having regular exercise, not brushing their teeth daily) also ate meals less regularly than those with more favourable habits. Again, smoking seems to be associated with other harmful behaviours like drinking fizzy drinks for quenching thirst and brushing teeth irregularly. It is notable that persons with unfavourable health habits most commonly ate only bread for meals compared with others. Actually, bread is an important part of the traditional Finnish diet and our results propose that proper meals are easy to replace with bread. A more harmful way than bread for replacing meals is consumption of different snacking products.

The drinking habits at meals of Finnish conscripts can be regarded as relatively healthy; only $12 \%$ consumed something else than milk or water. For quenching thirst, on the other hand, the juice consumption was surprisingly high (21\%) along with the consumption of fizzy and energy drinks. One-third of drinks for quenching thirst were something else than water or milk instead of the recommended water $^{(21)}$. Oral health among conscripts consuming water for quenching thirst was significantly better than among those consuming fizzy drinks. This was also reported earlier by Hasselkvist et al. ${ }^{(22)}$, who found that the Gingival Bleeding Index and DMFT values were higher among those 18-19-year-olds consuming fizzy drinks than the group with low fizzy drink consumption. In the present study, fizzy drink consumption was clearly most common among conscripts with lower educational level and, simultaneously, this group also ate daily meals least regularly and had most problems in oral health. Educational background in the family has found to be associated with oral health in previous studies ${ }^{(23,24)}$.

Obesity (BMI $\geq 35 \mathrm{~kg} / \mathrm{m}^{2}$ ) is one exclusion criterion for military service ${ }^{(25)}$ in Finland, but exclusion happens mostly after the obligatory health examination in the first weeks of military service. The data used in the present study were collected in the early phase of the conscripts' military service, so the answers regarding dietary habits and oral hygiene represent the behaviour before the service and include obese conscripts $\left(B M I=30-35 \mathrm{~kg} / \mathrm{m}^{2}\right)$, which is a benefit.

Here, a decreasing number of meals was associated with overweight, which is in line with a previous Finnish study $^{(26)}$. In fact, it seemed that those who eat more meals daily have better oral health conditions and are of normal weight. However, regular exercise had no particular effect on overweight in the present study. The study population was healthy young adults, with the majority doing regular physical exercise. The results here support the findings of 
Table $4 \mathrm{OR}$ and $95 \% \mathrm{Cl}$ from binary logistic regression analysis (adjusted) for the association of restorative dental treatment need (DT $>0$ ) or overweight $\left(\mathrm{BMI} \geq 25 \mathrm{~kg} / \mathrm{m}^{2}\right)$ with explanatory factors in the study population of $\sim 8700$ Finnish conscripts born in the beginning of the 1990s (data from the 'Oral Health of the Conscripts 2011' project)

\begin{tabular}{|c|c|c|c|c|}
\hline \multirow[b]{2}{*}{ Explanatory factor } & \multicolumn{2}{|c|}{$\mathrm{DT}>0$} & \multicolumn{2}{|c|}{$\mathrm{BMI} \geq 25 \mathrm{~kg} / \mathrm{m}^{2}$} \\
\hline & OR & $95 \% \mathrm{Cl}$ & OR & $95 \% \mathrm{Cl}$ \\
\hline \multicolumn{5}{|l|}{ Breakfast } \\
\hline No & 1.00 & Ref. & 1.00 & Ref. \\
\hline Yes & 0.86 & $0.78,0.95$ & 0.78 & $0.70,0.87$ \\
\hline \multicolumn{5}{|l|}{ Lunch } \\
\hline No & 1.00 & Ref. & 1.00 & Ref. \\
\hline Yes & 0.97 & $0.88,1.07$ & 0.93 & $0.84,1.04$ \\
\hline \multicolumn{5}{|l|}{ Dinner } \\
\hline No & 1.00 & Ref. & 1.00 & Ref. \\
\hline Yes & 0.90 & $0.80,1.01$ & 0.86 & $0.76,0.97$ \\
\hline \multicolumn{5}{|l|}{ Supper } \\
\hline No & 1.00 & Ref. & 1.00 & Ref. \\
\hline Yes & 1.09 & $0.98,1.02$ & 0.94 & $0.84,1.05$ \\
\hline \multicolumn{5}{|l|}{ Smoking } \\
\hline No & 1.00 & Ref. & 1.00 & Ref. \\
\hline Yes & 1.88 & $1.71,2.05$ & 1.19 & $1.07,1.31$ \\
\hline \multicolumn{5}{|c|}{ Water for quenching thirst } \\
\hline No & 1.00 & Ref. & 1.00 & Ref. \\
\hline Yes & 0.95 & $0.86,1.04$ & 1.08 & $0.97,1.21$ \\
\hline \multicolumn{5}{|c|}{ Fizzy drink for quenching thirst } \\
\hline No & 1.00 & Ref. & 1.00 & Ref. \\
\hline Yes & 1.38 & $1.15,1.66$ & 0.83 & $0.67,1.02$ \\
\hline \multicolumn{5}{|l|}{ Regular exercise } \\
\hline No & 1.00 & Ref. & 1.00 & Ref. \\
\hline Yes & 0.89 & $0.79,0.99$ & 1.05 & $0.93,1.19$ \\
\hline \multicolumn{5}{|l|}{ Daily tooth brushing } \\
\hline No & 1.00 & Ref. & 1.00 & Ref. \\
\hline Yes & 0.50 & $0.43,0.58$ & 0.85 & $0.73,1.00$ \\
\hline
\end{tabular}

DT, decayed teeth; ref., reference category.

Hooley et al. ${ }^{(10)}$, who reported that unfavourable eating and oral hygiene habits associate with overweight.

Overweight conscripts had worse oral health conditions by all indicators than their normal-weight counterparts. Similar findings about poorer oral health conditions among overweight people have been made in several other studies $^{(27-29)}$. The tendency of less regular tooth brushing among the overweight conscripts in the present study may furthermore increase their risk of dental diseases ${ }^{(30)}$.

In rural areas, meals were eaten slightly more frequently compared with the urban areas. A similar difference was observed between the Finnish- and Swedish-speaking municipalities: the Swedish-speaking conscripts clearly consumed all meals except for supper more often. This finding may be one cause for better oral health among the Swedish-speaking conscripts, observed by Kämppi et $a{ }^{(14)}$.

A great advantage of the present study is that the mandatory military service in Finland offered data collected on a unique age cohort, which is otherwise challenging to achieve. Additionally, health examination was obligatory, producing zero dropout rate. Annually about 25000 young men enter the service with a performance rate of $79 \%{ }^{(14)}$.
The participants here are a random sample of all draftees, thus representing the conscripts in 2011 of whom the majority were born in 1991 (>90\%).

Owing to the cross-sectional nature of the current study, we are not able to identify possible causal factors behind the oral health and BMI findings. Longitudinal studies on the topic would be valuable. The small proportion of females was included in the study population here, but it would be interesting to have a large-scale study with both genders. Also, it would be valuable to have all information about every conscript from both oral health screening and questionnaire. The questions about dietary habits based on Finnish meal recommendations and the questionnaire have been used in many other population-based Finnish studies $^{(8,15,31-39)}$. The computer-based questionnaire was initially created together with secondary students to investigate oral health-related behaviours for secondary-school students ${ }^{(8,31)}$. It was piloted before the study. It was piloted again for the conscript study and validated ${ }^{(15,32-36)}$. In addition, the modified version of the questionnaire has been used in many other population-based Finnish studies $^{(32,33,35,36)}$. There was no chance for keeping a diet diary to investigate diet composition. The questionnaire does not give details of the diet (such as percentage of energy from free sugars) but rather presents patterns of eating.

From the present study on the dietary habits of the Finnish male population born in the early 1990s, it can be concluded that the most important factors associated with dental health are behavioural ones like irregular meals, drinking fizzy drinks, smoking and irregular teeth brushing. The same variables are also associated with overweight. Programmes battling overweight and promoting oral health among adolescents in countries with low dental caries experience should be continued, to achieve life-long good oral health. Regularity - be in eating, hygiene or hygiene habits - is an important factor for maintaining oral health and normal weight.

\section{Acknowledgements}

Acknowledgements: The authors gratefully acknowledge the dental staff at the dental clinics of the Finnish Defence Forces for their enthusiasm and work in conducting the field survey. They also want to express thanks to Mrs Mari Saario at the Centre for Military Medicine, Finnish Defence Forces, for her cooperation in collecting data. Financial support: This research received no specific grant from any funding agency in the public, commercial or not-for-profit sectors. Conflict of interest: None. Authorship: This study was designed and conducted by T.T., P.M. and V.A. T.T. is the corresponding author. J.P. is the statistical advisor and also active writer as well as T.T., P.M., P.P., L.T. and V.A. All authors have read and approve of the final version of manuscript. Ethics of human 
subject participation: This study was conducted according to the guidelines laid down in the Declaration of Helsinki and all procedures involving human subjects were approved by the Ethical Committee of the Northern Ostrobothnia Hospital District, which issued a positive statement on the plan on 29 March 2010. The Centre for Military Medicine and the Finnish Defence Forces staff also gave their permission for the study in June 2010 (AG14218/ 23 June 2010). Written informed consent was obtained from all subjects. The conscripts gave their consent to use their patient records by answering the voluntary computer-assisted questionnaire. De-identified data were used for the analyses.

\section{References}

1. Bratthall D, Hänsel-Petersson G \& Sundberg H (1996) Reasons for the caries decline: what do the experts believe? Eur J Oral Sci 104, 416-422.

2. Tomofuji T, Furuta M, Ekuni D et al. (2011) Relationships between eating habits and periodontal condition in university students. J Periodontol 82, 1642-1649.

3. Moynihan P \& Kelly S (2014) Effect on caries of restricting sugar intake: systemic review to inform WHO guidelines. J Dent Res 93, 8-18.

4. Popkin B, Adair L \& Ng S (2012) Global nutrition transition and the pandemic of obesity in developing countries Nutr Rev 70, 3-21.

5. Ruottinen S, Karjalainen S, Pienihäkkinen K et al. (2004) Sucrose intake since infancy and dental health in 10-yearold children. Caries Res 38, 142-148.

6. Lukkari E, Myöhänen J, Anttonen V et al. (2008) Dietary and oral hygiene habits: room for improvement among schoolchildren. Finn Dent J 15, 22-27.

7. Helldán A, Raulio S, Kosola M et al. (2013) The National FINDIET 2012 Survey. NIH Report no. 16/2013 (in Finnish with an English summary). Helsinki: National Institute for Health and Welfare; available at https://www.julkari. fi/bitstream/handle/10024/110839/THL_RAP2013_016_\%26 sliitteet.pdf?sequence $=1$ (accessed April 2019).

8. Anttonen V, Seppä L, Niinimaa A et al. (2011) Dietary and oral hygiene intervention in secondary school pupils. Int J Paediatr Dent 21, 81-88.

9. Ovaskainen ML, Reinivuo H, Tapanainen H et al. (2006) Snacks as an element of energy intake and food consumption. Eur J Clin Nutr 60, 494-501.

10. Hooley M, Skouteris H \& Millar L (2012) The relationship between childhood weight, dental caries and eating practices in children aged 4-8 years in Australia, 2004-2008. Pediatr Obes 7, 461-470.

11. Vuorela N, Saha M \& Salo M (2011) Change in prevalence of overweight and obesity in Finnish children - comparison between 1974 and 2001. Acta Pediatr 100, 109-115.

12. Zeigler C, Persson G, Wondimu B et al. (2012) Microbiota in the oral subgingival biofilm is associated with obesity in adolescents. Obesity (Silver Spring) 20, 157-164.

13. Tanner T, Kämppi A, Päkkilä J et al. (2013) Prevalence and polarization of dental caries among young, healthy adults: cross-sectional epidemiological study. Acta Odontol Scand 71, 1436-1442.

14. Kämppi A, Tanner T, Päkkilä J et al. (2013) Geographical distribution of dental caries prevalence and associated factors in young adults in Finland. Caries Res 47, 346-354.
15. Anttonen V, Tanner T, Kämppi A et al. (2012) A methodological pilot study on oral health of Finnish young males. Dent Hypotheses 3, 106-111.

16. Tanner T, Päkkilä J, Karjalainen K et al. (2015) Smoking, alcohol use, socioeconomic background and oral health among young Finnish adults. Community Dent Oral Epidemiol 43, 406-414.

17. Finnish Food Authority (2014) Finnish Nutrition Recommendations (in Finnish). Helsinki: Finnish Food Authority; available at https://www.ruokavirasto.fi/ globalassets/teemat/terveytta-edistava-ruokavalio/kuluttajaja-ammattilaismateriaali/julkaisut/ravitsemussuositukset_2014_ fi_web_versio_5.pdf (accessed April 2019).

18. Dusseldorp E, Kamphuis M \& Schuller A (2015) Impact of lifestyle factors on caries experience in three different age groups: 9, 15, and 21-year-olds. Community Dent Oral Epidemiol 43, 9-16.

19. Bruno-Ambrosius K, Swanholm G \& Twetman S (2005) Eating habits, smoking and toothbrushing in relation to dental caries: a 3-year study in Swedish female teenagers. Int J Paediatr Dent 15, 190-196.

20. Cinar AB, Christensen LB \& Hede B (2011) Clustering of obesity and dental caries with lifestyle factors among Danish adolescents. Oral Health Prev Dent 9, 123-130.

21. Valsta L, Borg P, Heiskanen S et al. (2008) Drinks in Diet. Report of the National Board of Nutrition (in Finnish). Helsinki: Yliopistopaino; available at https:// www.ruokavirasto.fi/globalassets/teemat/terveytta-edistavaruokavalio/kuluttaja-ja-ammattilaismateriaali/julkaisut/ juomat_ravitsemuksessa.pdf (accessed July 2019).

22. Hasselkvist A, Johansson A \& Johansson AK (2014) Association between soft drink consumption, oral health and some lifestyle factors in Swedish adolescents. Acta Odontol Scand 72, 1039-1046.

23. Buchwald S, Kocher T, Biffar R et al. (2013) Tooth loss and periodontitis by socioeconomic status and inflammation in a longitudinal population-based study. J Clin Periodontol 40, 203-211.

24. Costa S, Martins C, Bonfim M et al. (2012) A systematic review of socioeconomic indicators and dental caries in adults. Int $J$ Environ Res Public Health 9, 3540-3574.

25. Pääesikunta/Logistiikkaosasto (2012) Terveystarkastusohje TTO, p. 55 (in Finnish). Tampere: Edita Juvenes Print Oy; available at http://puolustusvoimat.fi/documents/1948673/ 2258811/PEVIESTOS-Terveystarkastusohje2012.pdf/d8fec 7e9-1178-44bf-8b6e-cdd9fd585ec3 (accessed April 2019).

26. Jääskeläinen A, Schwab U, Kolehmainen M et al. (2013) Associations of meal frequency and breakfast with obesity and metabolic syndrome traits in adolescents of Northern Finland Birth Cohort 1986. Nutr Metab Cardiovasc Dis 23, 1002-1009.

27. Willershausen B, Moschos D, Azraj B et al. (2007) Correlation between oral health and body mass index (BMI) in 2071 primary school pupils. Eur J Med Res 12, 295-299.

28. Benguigui C, Bongard V, Ruidavets JB et al. (2012) Evaluation of oral health related to body mass index. Oral Dis 18, 748-755.

29. Hayden C, Bowler JO, Chambers S et al. (2013) Obesity and dental caries in children: a systematic review and metaanalysis. Community Dent Oral Epidemiol 41, 289-308.

30. Löe H (2000) Oral hygiene in the prevention of caries and periodontal disease. Int Dent J 50, 129-139.

31. Anttonen V, Hausen H, Seppä L et al. (2008) Effect of dietary habits on laser fluorescence values of visually sound occlusal surfaces among Finnish schoolchildren. Int J Paediatr Dent 18, 124-130.

32. Tanner T, Kämppi A, Päkkilä J et al. (2014) Association of smoking and snuffing with dental caries occurrence in a young male population in Finland: a cross-sectional study. Acta Odontol Scand 72, 1017-1024. 
33. Kämppi A, Päkkilä J, Tanner T et al. (2014) Validity of a questionnaire in estimating restorative treatment need among young adults. Community Dent Health 31, 245-250.

34. Anttonen V, Sarkkinen A, Niinimaa A et al. (2014) Dietary and oral hygiene habits of young athletes. Int J Paediatr Dent 24, 358-366.

35. Tanner T, Päkkilä J, Karjalainen K et al. (2015) Smoking and alcohol use in association with oral health of a group of young males. Community Dent Oral Epidemiol 43, 406-414.

36. Kämppi A, Päkkilä J, Tanner T et al. (2016) Comparison of simple screening criteria with the International Caries
Detection and Assessment System classification in determining restorative treatment need. Int Dent J 66, 63-70.

37. Mattila A, Ghaderi P, Tervonen L et al. (2016) Self-reported dental health and use of dental services among asylum seekers and immigrants in Finland - a pilot study. Eur J Public Health 26, 1006-1010.

38. Alaraudanjoki V, Laitala ML, Tjäderhane L et al. (2016) Influence of intrinsic factors on erosive tooth wear in a large-scale epidemiological study. Caries Res 50, 508-516.

39. Vainionpää R, Peltokangas A, Leinonen J et al. (2017) Oral health and oral health-related habits of Finnish prisoners. BDJ Open 3, 17006. 